\title{
PRONTUÁRIO ELETRÔNICO DO PACIENTE: REVISÃO DE LITERATURA
}

\author{
Luan Barbosa Hubner ${ }^{1}$ \\ Juliana Facchini de Souza ${ }^{2}$ \\ Marcio Jose Sembay ${ }^{3}$ \\ Ingrid Solange Sepúlveda Muñoz ${ }^{4}$
}

Resumo: O prontuário eletrônico é uma ferramenta de grande auxilio para gestão em unidade básica de saúde (UBS), hospitais e clinicas. Quando falamos de prontuário eletrônico percebemos que possui vários nomes, como: Prontuário do Paciente, Prontuário Familiar, Prontuário Médico, Prontuário Hospitalar, Registro do Paciente entre outros. Com a ideia de melhorar o atendimento dos pacientes, garantir segurança para os dados e manter um histórico do paciente da sua vida toda, se seu uso for bem trabalhado com cuidado e alimentado o sistema corretamente irá ser de grande aproveitamento e ajuda para a instituição. Diante disto o objetivo do presente estudo é uma revisão de literatura, para avaliar a eficácia da implantação de um prontuário eletrônico. Nenhum estudo mostrou que o prontuário teve efeito negativo em sua implantação, apenas apresenta algumas desvantagens, sendo a implantação do prontuário eletrônico de grande valia em UBS que ainda não os possuem.

Palavras-chave: Prontuário eletrônico; PEP; Prontuário do Paciente.

\footnotetext{
1 Ciência da Computação, Centro Universitário Unifacvest, Brasil. E-mail: guitarmak43@gmail.com.

2 Ciência da Computação, Centro Universitário Unifacvest, Brasil. E-mail: jufacchini1@gmail.com.

${ }^{3}$ Ciência da Computação, Centro Universitário Unifacvest, Brasil. E-mail: m_sembay@yahoo.com.br.

${ }^{4}$ Ciência da Computação, Centro Universitário Unifacvest, Brasil. E-mail: ismunoz3@gmail.com.
} 